\title{
Strategic Export Policy in the Presence of Subcontracting
}

\author{
Ho-Chyuan Chen \\ National Kaohsiung First University of Science and Technology \\ Wen-Jung Liang \\ Tamkang University
}

\begin{abstract}
This paper examines the optimal export policies when ex ante negotiation over subcontract manufacturing occurs between two competing international-firms. It show that it could be optimal for the exporting country to adopt either a different or a parallel trade policy between the two exporting goods (the final product and the subcontracted product). However, a different trade policy that taxes the finalproduct export and subsidizes the subcontracted-product export is not ever optimal. When the exporting firm is a pure subcontractor, taxing the single export (subcontracted product) becomes the only optimal trade policy of the exporting country. Morever, the exporting country imposes a less aggressive trade policy in response given that the importing country inflicts a more aggressive trade policy.
\end{abstract}

- JEL classification: F13 and L13

- Keywords: Subcontracting, International Trade, Nash Bargaining, Trade Policy

\footnotetext{
*Corresponding address: Ho-Chyuan Chen, Department of Risk Management and Insurance, National Kaohsiung First University of Science \& Technology, Nantz, Kaohsiung City 811, Taiwan; E-mail address: hcchen@ccms.nkfust.edu.tw; Fax: 886-7-6011039; Tel: 886-7-6011000 Ext. 3024.

**Financial support from the Taiwan National Science Council is gratefully acknowledged.

@ $2007-C e n t e r$ for International Economics, Sejong Institution, All Rights Reserved.
} 


\section{Introduction}

Subcontracting has become an increasingly popular method for firms to avoid the increasing opportunity costs of in-house production. Subsequently, international subcontracting has also become a common economic phenomenon globally. Hummels, Ishii, and Yi (2001) provide evidence that international outsourcing grew approximately $30 \%$ between 1970 and 1990. Some notable examples are IBM and Dell, who subcontract all their PC production to their overseas subcontracting suppliers. In the automobile industry, American car producers and European car producers subcontract about $50 \%$ of their products to subcontractors, while the figure is about $75 \%$ in Japan's automobile industry (Ikeda, 1989). The picture changed according to Grossman and Helpman (1999), who point out that only about $37 \%$ of the production value of American cars was produced in the United States. In the mobile phone industry, Nokia is estimated to use more than 300 domestic subcontractors, as well as almost the same number of international subcontractors (Shy and Stenbacka, 2003).

One of the reasons for international subcontracting by firms in advanced economies is that the production is cheaper in developing countries, which could be due to the economies of scale and cheaper labor costs. For example, Radio Shack and Texas Instruments have commissioned firms in developing countries to produce components or entire products, which are then sold under the consignors' names (Pack and Saggi, 2001). TopsyTail, a hair-styling devices company in the United States, had virtually no permanent employers, thereby its major functions, such as design, manufacturing, marketing, distribution, and packaging, were performed by subcontractors (The Economist, 1995). In the computer industry, it was estimated that about $90 \%$ of the overseas subcontracting orders of Compaq, Hewlett-Packard (before their merger), and Apple went to Taiwan (Fubon Investment Service, 2002). In fact, Taiwan's notebook computer industry has about $90 \%$ of total sales from subcontracting production, while the figure is more than about $80 \%$ in the PC industry (MIC, 2002). In the semiconductor foundry industry it is even more evident with TSMC and UMC in Taiwan becoming the largest international subcontractors.

The issue of international trade policy when firms involve international subcontracting has not received sufficient attention in the literature. A foreign subcontractor produces the subcontracted product for the domestic consignor, which competes with the foreign subcontractor in the final product market (if it has its own brand and if it exports to the domestic country). Acer in Taiwan, for 
example, while producing computers for IBM and Dell, sells its own brand in the United States. Therefore, the international subcontracting involves not only a firm's cost-savings motive but also a firm's strategic motive. For a country to pursue maximum welfare, it has to strategically consider the trade policy when international subcontracting gets involved.

To explore the effect of subcontracting on trade policy, we consider a three-stage game model with ex ante contracting. There are two firms, 1 and 2, competing for sales of their final products in the market of country 2. Firm 1 (the low-cost firm) produces at a constant marginal cost in country 1 and exports to country 2 , whereas firm 2 (the high-cost firm) in country 2 produces at an increasing marginal cost. In stage 1 they both negotiate over a subcontract over which part of firm 2's production of its expected output is consigned to firm 1 at the expense of a transfer payment, and then production takes place. In stage 2 the part of firm 2's output consigned to firm 1 for production (which we refer to as the subcontracted product) is delivered to firm 2, and then both firms Cournot-compete in country 2's market for sales of the their final products. ${ }^{1,2}$ Prior to stage 1 , three trade policies are considered: country 1's subsidy on the downstream export, and a tax on the subcontracted export, and country 2's tariff on the subcontracted import (from country 1). ${ }^{3,4}$

\footnotetext{
${ }^{1}$ Accordingly, we refer to firm 1 (country 1 ) as the exporting firm (country) and firm 2 (country 2 ) as the importing firm (country).

${ }^{2}$ Subsequently, three different types of goods are classified in this paper. "The downstream products" refer to those products sold directly to consumers in the market competition (which exists only in the importing country); "the upstream products" refer to those products sold to other firms which then resell them to consumers in the market with or without value added; "the subcontracted products" refer to the part of firm 2's downstream output which is cosigned to firm 1 for production and then is delivered to firm 2, at the expense of a transfer payment to firm 1 according to a subcontract. Therefore, a subcontracted product, in some sense, can be seen as a form of an upstream product or an intermediate good (as in Spencer and Brander, 1983; Spencer and Jones, 1991; and Chen, Ishikawa, and Yu, 2004). Moreover, for simplicity throughout the paper, we refer to the downstream exports (imports) and the subcontracted exports (imports) as the exporting (importing) downstream products and the exporting (importing) subcontracted products, respectively.

${ }^{3}$ Although the World Trade Organization prohibits export subsidies, we consider a subsidy as a trade policy, because as Collie (1997) argues, many industrialized countries use export credits and export credit insurance to give their firms an advantage for exporting capital goods to developing countries.

${ }^{4}$ In Section 2 for the model setup, we assume that the subcontracted product is partitioned into parts and exported in the form of intermediate goods. The consignor (importing firm) then assembles these intermediate goods with a comparatively small and negligible cost into already-built capacity (because the consignor produces the downstream product as well). Therefore, the downstream product and the subcontracted product are justifiably distinguishable for different export trading policies.
} 
Ex ante subcontracting under Nash bargaining in our paper is in contrast to $e x$ post subcontracting in Liang, Chen, and Shi (2003, LCS hereafter) and no any subcontract-negotiation in Spencer and Jones (1991). ${ }^{5}$ Ex ante subcontracting is sure to be a better fit in many real cases. Firms, which are usually forward looking, estimate the expected market demand and expected market share for the next period and then take action (including investment and subcontracting) to be ready for the next period's competition. Therefore, it is more reasonable to have subcontracting set up before competition takes place. As Spiegel (1993, p571) says, "Typically, contracts are treated in the industrial organization literature as long-term decisions while quantities and prices are treated as short-term decisions. Accordingly, the competitive effects of contracts are often examined in the framework of two-stage models, in which contracts are set in the first stage and competition takes place in the second." Ex ante subcontracting basically increases the importing firm's total output of the final good when the subcontracted quantity increases. This is because the ex ante contract in our paper leads to a split in the cooperation profit through a transfer payment. ${ }^{6}$

Subcontracting can be very strategic and it significantly alters the incentives for the international trade policy, which is the main discussion of this paper. Chen, Ishikawa, and $\mathrm{Yu}$ (2004) focus on the effects of trade liberalization (which is represented by reduction in tariffs) on firms' behaviors when subcontracting is strategically employed, leaving out the issue of optimal trade policy. ${ }^{7,8}$ Whereas Spencer and Jones (1991) discuss the optimal trade policy, they do not include the

\footnotetext{
${ }^{5}$ According to Spiegel (1993), two variant models for studying subcontracting are classified. The model of ex post subcontracting sets downstream quantities in the market competition before the signing of a subcontract, while the model of ex ante subcontracting has firms sign the subcontract before they compete in the downstream market.

${ }^{6}$ In contrast, LCS (with ex post contracting) leads both firms to cooperate on minimizing cost (since the Cournot output has been set when they are bargaining).

${ }^{7}$ Their model has two stages. In the first stage, with given the importing country's specific tariffs on both downstream good and upstream good, the exporting firm (with a lower marginal cost) chooses a price for the upstream good and the importing firms decides whether to contract to buy the upstream good from the exporting firm. In the second stage, both firms compete in price for the downstream good in the importing country. In contrast to the common view in the current literature, they find that further liberalization (i.e., further tariff reduction) in the upstream good raises the prices of both the upstream and the downstream goods.

${ }^{8}$ For more about issue of subcontracting, readers can refer to Kamien et al. (1989), Spiegel (1993), and Shy and Stenbacka (2003).
} 
issue of international subcontracting. They claim that for an exporting country it is optimal to impose a parallel trade policy on its intermediate good and its final good, but it is never a possibility to impose any different trade policy. ${ }^{910}$ LCS (2003) take into account an ex post subcontract and find that it is never optimal for the exporting country to subsidize both the exports of the final good and the subcontracted good. ${ }^{11}$ Instead, our paper assumes ex ante subcontracting and finds that it could be optimal for the exporting country to impose either a parallel trade policy, or a different trade policy that subsidizes the downstream export and taxes the upstream export. A different trade policy, which taxes downstream export and subsidizes upstream export, is never an optimal policy. ${ }^{12}$ Moreover, when the downstream export is foreclosed, our paper finds that taxing the single export is the only optimal trade policy for the exporting country, whereas Spencer and Brander (1983) find that the definite optimal policy is to subsidize the single export to help the domestic firm capture a larger share of the imperfectly competitive rent. ${ }^{13}$

The rest of the paper is organized as follows. Section 2 describes the basic model. Section 3 specifies the comparative statics. Section 4 explores the optimal policy of an exporting country, while a case with an exporting firm having a very high marketing cost is shown in Section 5. Section 6 contains concluding remarks.

\footnotetext{
${ }^{9}$ In their model, the exporting country sets trade policies first on the two exports (i.e., the intermediate good and the final good), then the exporting firm chooses its price for the intermediate good, and finally both firms Cournot-compete for sales of the final good in the importing country.

${ }^{10}$ For an exporting country that has both the downstream export and the subcontracted export, a different trade policy refers to when the exporting country imposes a tax on either one of the two exports and offers a subsidy on the other. Contrarily, a parallel trade policy refers to when the exporting country imposes either a tax or a subsidy on both of the exports.
${ }^{11}$ In their model the exporting country sets trade policies first on the two exports (i.e., the subcontracted good and the final good), the firms next Cournot-compete in the importing country for the sales of the final good, and then they negotiate over the subcontracting agreement, manufacture the products, and deliver the subcontracted good.
${ }^{12}$ Due to different model setting-ups, the determination of the upstream good's price is also different. Through Nash bargaining, the price of the subcontracted good is endogenous in our paper, whereas the price (of the intermediate good) is simply given by the exporting firm in Spencer and Jones (1991).

${ }^{13}$ Spencer and Brander (1983) assume that both firms, each in one country, export the final goods and compete in a third country. For more discussions about related international trade issues, readers can also refer to Brander and Spencer (1981, 1984a, 1984b, 1985), Holm (1997), and Spencer and Jones (1992).
} 


\section{The Model}

Firm 1 (in country 1) and firm 2 (in country 2) produce $x_{1}$ and $x_{2}$, respectively, and compete only in country 2 for sales of the good. For the sake of cost savings, one firm may subcontract out part of the production of its quantity to the other firm. We denote $x_{s}$ as the subcontracted quantity consigned to firm 1 from firm 2 at the price of $T$ (transfer payment), which is assumed to be determined through a Nash bargaining process. We will refer to competition for sales of the final goods in country 2 as the downstream market and refer to the subcontracting process and production as the upstream market.

In the downstream market the price of the importing country's downstream product is determined by the inverse demand function $p=a-x$, where $x=x_{1}+x_{2}$ represents the aggregate downstream quantities. The ensuing marginal marketing cost of firm $i$ is denoted by $m_{i}$, for $i=1,2{ }^{14}$

In the upstream process, firm $i$ 's production cost $C_{i}$ can be described as $C_{1}=c_{1}$. $\left(x_{1}+x s\right)$, and $C_{2}=C_{2}\left(x_{2}-x_{s}\right)=\beta\left(x_{2}-x_{s}\right)+1 / 2\left(x_{2}-x_{s}\right)^{2}$, where coefficients $c_{1}$ and $\beta$ are constants and $C_{2}\left(x_{2}-x_{s}\right)$ is increasing and convex in $\left(x_{2}-x_{s}\right)$, which is the importing firm's real producing quantity. ${ }^{15}$

A three-stage game for the international trade policy decision is now constructed. In the prior stage the exporting country imposes a specific subsidy $\sigma$ and a specific tax $v$ on exports of the downstream product and the subcontracted product respectively, while the importing country imposes a tariff $t$ on the import of the downstream product. In stage 1 the two firms sign a subcontracting agreement, according to which firm 1 produces $x_{s}$ units of subcontracted quantities for firm 2 (i.e., the high-cost rival firm), and in return it receives a transfer payment $T .{ }^{16} \mathrm{We}$ assume that the agreement on both $x_{s}$ and $T$ is reached through Nash bargaining solution. ${ }^{17}$ Lastly in stage 2, the subcontract is enforced, the subcontracted product

\footnotetext{
${ }^{14}$ The marketing cost $m_{i}$ of own brand $x_{i}$ includes the costs of advertising, the sales network, and marketing, etc. This may be too high for the exporting firm (i.e., firm 1) to enter the downstream market, as one can see in the discussion in Section 5.

${ }^{15}$ Without loss of generality, the importing firm's cost function is assumed to have a quadratic form, and the coefficient of the quadratic term is set as $1 / 2$, so as to derive a clearer result.

${ }^{16}$ Therefore, we can express $T$ as $T\left(x_{s}\right)$. When $x_{s}=0, T=0$.

${ }^{17}$ We show in the Appendix, this assumption is equivalent to the assumption in Spiegel (1993), which lets firms jointly choose the contracted quantity to maximize joint profits and lets Nash-bargaining take place only with respect to the choice of transfer payment.
} 
is delivered to the importing firm, and both firms engage in a Cournot competition in the importing country's (i.e., country 2's) downstream market.

For the downstream product and the subcontracted product to be justifiably distinguishable for different export trading policies of the exporting country, we assume that, without loss of generality, the subcontracted product is partitioned into parts and exported in the form of intermediate goods. The consignor (importing firm) then assembles these intermediate goods with a comparatively small and negligible cost, because the consignor produces the downstream product as well and the assembly takes place in the already-built capacity. Note that we also assume the exporting firm does not have already-built capacity in the importing country to assemble parts, implying that it is costly for the exporting firm to export parts rather than the downstream final product. Indeed, this approach is commonly utilized for many importers, such as automobile importers, to reduce their tariff payments due to the fact that the tariff on the final product is much higher than on the parts.

\section{Comparative Statics}

By backward induction we begin the analysis with stage 2 (the downstream stage), in which the two firms engage in Cournot competition, given their subcontracting agreement (according to which the subcontracted quantity $x_{s}$ of the importing firm consigned to the exporting firm and the transfer payment $T$ from the importing firm to the exporting firm are both fixed). Assuming no fixed costs, each firm thus has the following profit function:

$$
\begin{aligned}
\bar{\pi}^{1}=\pi^{1}+T & =\left(p+\sigma-t-m_{1}\right) x_{1}-c_{1}\left(x_{1}+x_{s}\right)-v x_{s}+T\left(x_{s}\right) \\
& =\left(p+\sigma-t-m_{1}-c_{1}\right) x_{1}+\left[T\left(x_{s}\right)-\left(c_{1}+v\right) x_{s}\right] . \\
\bar{\pi}^{2}=\pi^{2}-T & =\left(p-m_{2}\right) x_{2}-\beta\left(x_{2}-x_{s}\right)-\frac{1}{2}\left(x_{2}-x_{s}\right)^{2}-T\left(x_{s}\right) \\
& =\left(p-m_{2}-\beta-\frac{1}{2} x_{2}\right) x_{2}+\left[\left(\mathrm{x}_{2}-\frac{1}{2} x_{s}+\beta\right) x_{s}-T\left(x_{s}\right)\right] .
\end{aligned}
$$

Notation $\pi^{i}$ denotes firm $i$ 's before-transfer profit, while $\bar{\pi}$ is its after-transfer profit or net profit. The exporting firm's profit is the total revenue of the exporting downstream product minus its marketing cost, total upstream production cost, and net exporting tax payment, while adding the transfer payment for the subcontracting 
production. This can be represented, as shown in the second equality of (1), by the profit sum of sales of the downstream product and gains of the subcontracted product. On the other hand, the importing firm's profit is obtained by subtracting from its revenue the marketing cost, the upstream production cost, and the transfer payment, which can be alternatively represented by the profit sum of sales of the downstream product and cost savings of the subcontracted product.

Each firm decides the downstream quantity to maximize their profits (1) and (2), given $T\left(x_{s}\right)$ and $x_{s}$. Thus, with respect to $x_{1}$ and $x_{2}$, we obtain the first-order conditions as in equation (3) and (4), respectively:

$$
\begin{gathered}
\bar{\pi}_{1}^{1}=\pi_{1}^{1}=\left(p+\sigma-t-m_{1}-c_{1}\right)-x_{1}=0 . \\
\bar{\pi}_{2}^{2}=\pi_{2}^{2}=\left(p-m_{2}\right)-x_{2}-\beta-\left(x_{2}-x_{s}\right)=0 .
\end{gathered}
$$

When the subcontracted quantity $x_{s}$ increases, firm 2's marginal production cost decreases, causing more $x_{2}$ output. The increase of $x_{2}$ in turn leads to less $x_{1}$ output under Cournot competition. Denote $\tilde{x}_{1}$ and $\tilde{x}_{2}$ as the Cournot outputs, respectively, of each firm in the case of no subcontracting, i.e., when $x_{s}=0 .{ }^{18} \mathrm{By}$ solving (3) and (4) simultaneously, we obtain the Cournot equilibrium output as follows: ${ }^{19}$

$$
\begin{aligned}
x_{1} & =\tilde{x}_{1}-\frac{1}{5} x_{s}, \text { and } x_{2}=\bar{x}_{2}+\frac{2}{5} x_{s}, \\
\text { where } \tilde{x}_{1} & =\frac{2}{5} a+\frac{3}{5}\left(\sigma-t-m_{1}-c_{1}\right)+\frac{1}{5}\left(m_{2}+\beta\right), \\
\tilde{x}_{2} & =\frac{1}{5} a-\frac{1}{5}\left(\sigma-t-m_{1}-c_{1}\right)-\frac{2}{5}\left(m_{2}+\beta\right) .
\end{aligned}
$$

When subcontracted quantity $x_{s}$ increases, firm 2's marginal production cost decreases, leading to a larger $x_{2}$ output and thus a lower $x_{1}$ output. That is, $x_{1}<\tilde{x}_{1}$, and $x_{2}>\tilde{x}_{2}$. Since firm 1 exhibits a constant marginal production cost, the average marginal production cost of the market decreases, resulting in an increase in total market output, as Lemma 1 states. Moreover, in (5) we see that one unit of $x_{s}$ change brings up a bigger effect on the output of $x_{2}$ than $x_{1}(2 / 5>1 / 5)$, because firm

\footnotetext{
${ }^{18}$ Notation " $\sim$ " hereafter denotes those variables derived from Cournot competition in the case of no subcontracting (i.e., denotes those non-cooperation variables).

${ }^{19}$ The second-order conditions for maximization are satisfied: $d^{2} \pi^{1} / d\left(x_{1}\right)^{2}=-2<0, d^{2} \pi^{2} / d\left(x_{2}\right)^{2}=-3<0$, and $H=5>0$.
} 
2 exhibits a convex cost function.

Lemma 1. When a subcontract is signed, the total market output increases.

Proof. Equation (5) readily shows that $x_{1}+x_{2}=\tilde{x}_{1}+\tilde{x}_{2}+\frac{1}{5} x_{s}$.

In stage 1, when expecting stage 2's Cournot outcome, the firms negotiate over the subcontract, according to which firm 1 produces quantity $x_{s}$ for firm 2 , and firm 2 pays a transfer $T$ to firm 1 . In order to focus on the analysis of trade policy, we assume equal bargaining power under the Nash bargaining solution for simplicity. In the Appendix, we show that the Nash bargaining over both $x_{s}$ and $T$ is equivalent to that firms choose $x_{s}$ to maximize joint profit $(\pi)$ as well as efficiently split the joint profit through the Nash bargaining over $T$. Through maximizing the joint profit, we obtain the first-order condition with respect to $x_{s}$ in equation (6), while the transfer payment $T$ is shown in (A3) under the Nash bargaining solution.

$$
\begin{aligned}
\frac{d \pi}{d x_{s}} & =\frac{d\left(\pi^{1}+\pi^{2}\right)}{d x_{S}}=\left(\frac{\partial \pi^{1}}{\partial x_{2}} \frac{\partial x^{2}}{\partial x_{s}}+\frac{\partial \pi^{1}}{\partial x_{s}}\right)+\left(\frac{\partial \pi^{2}}{\partial x_{1}} \frac{\partial x^{1}}{\partial x_{s}}+\frac{\partial \pi^{2}}{\partial x_{s}}\right) \\
& =\left[-\frac{2}{5} x_{1}-\left(c_{1}+v\right)\right]+\left[\frac{1}{5} x_{2}+\left(\beta+x_{2}-x_{s}\right)\right]=0
\end{aligned}
$$

The subcontracted quantity $x_{s}$ as a cooperative apparatus helps the cooperation reach maximum joint profit if, for one additional unit of $x_{s}$, firm 1's profit decrease equals firm 2's profit increase. When $x_{s}$ increases, firm 1's total cost increases (leading firm 1 to have lower profits) and firm 2's output also increases (leading to a lower market price). The former is the so-called direct effect $\left(\partial \pi^{1} / \partial x_{s}\right)$, while the latter is the strategic effect $\left(\partial \pi^{1} / \partial x_{2} \times \partial x_{2} / \partial x_{s}\right){ }^{20}$ Both of these two effects cause a decrease in firm 1's profit $\left(d \pi_{1} / d x_{s}<0\right)$, while causing an increase to firm 2's profit $\left(d \pi_{2} / d x_{s}>0\right)$. Since firm 2 benefits from subcontracting, it needs to make a transfer payment to firm $1 .^{21}$

\footnotetext{
${ }^{20}$ For firm $j$, the direct effect by the controlled variable $k$ is just the direct impact on firm $j$ 's profit given by $k$, i.e., $\partial \pi^{j} / \partial k$. The strategic effect is the indirect impact on firm $j$ 's profit given by firm $i$ 's output change due to the change of controlled variable $k$, and this can be expressed as $\left(\partial \pi^{j} / \partial x_{i}\right)\left(\partial x_{i} / \partial k\right)$. Moreover, $\partial \pi^{j} / \partial x_{i}$ is negative, because firm $i$ 's output increase leads to the market price decreasing, and hence firm $j$ 's revenue (and profit) decreases, which is larger in absolute value if firm $j$ has a larger output.
}

\footnotetext{
${ }^{21}$ The amount of transfer payment is shown in equation (A3).
} 
Solving (6) and substituting for (5), we obtain the optimal subcontracted quantity and the optimal output for each firm:

$$
\begin{aligned}
& x_{s}=\frac{2}{11} a-\frac{12}{11}\left(\sigma-t-m_{1}\right)-\frac{13}{11} c_{1}-\frac{14}{11} m_{2}+\beta-\frac{25}{11} v . \\
& x_{1}=\frac{4}{11} a-\frac{9}{11}\left(\sigma-t-m_{1}\right)-\frac{4}{11} c_{1}+\frac{5}{11} m_{2}+\frac{5}{11} v, \text { and } \\
& x_{2}=\frac{3}{11} a-\frac{7}{11}\left(\sigma-t-m_{1}\right)+-\frac{3}{11} c_{1}-\frac{10}{11} m_{2}-\frac{10}{11} v .
\end{aligned}
$$

Equation (8) shows that if firm 1's marginal cost for $x_{1}$ becomes relatively small (e.g., an increase of $\sigma, m_{2}, v$, and/or $\beta$, and a decrease of $t$ and/or $m_{1}$ ), then it is more profitable for firm 1 to produce and sell $x_{1}$. Therefore, $x_{1}$ increases and $x_{s}$ decreases, leading to a decrease in $x_{2}$ under Cournot competition. However, when $c_{1}$ decreases, $x_{1}$ increases and $x_{s}$ also increases, because there are better cost-savings for firm 2 under subcontracting cooperation, which then leads $x_{2}$ to increase.

\section{Optimal Trade Policy of the Exporting Country}

Because the final good $x$ is only sold in the importing country, the exporting country's welfare (denoted as $\left.w^{1}\right)$ is equal to the exporting firm's net profit $\left(\bar{\pi}^{-1}\right)$ minus the government's net subsidy $\left(\sigma x_{1}-v x_{s}\right.$, denoted as $S$ hereafter):

$$
\begin{gathered}
w^{1}=\bar{\pi}^{1}-S, \\
\text { where } \bar{\pi}^{1}=\tilde{\pi}^{1}+\frac{1}{2} \Delta \pi \text {, and } S=\sigma x_{1}-v x_{s} .
\end{gathered}
$$

In the prior stage the exporting country chooses export policies to maximize its welfare. With respect to $\sigma$ and $v$, the first-order conditions of the welfare function are as follows:

$$
\begin{gathered}
w_{\sigma}^{1}=\bar{\pi}_{\sigma}^{1}-S_{\sigma}=\tilde{\pi}_{\sigma}^{1}+\frac{1}{2}(\Delta \pi)_{\sigma}-S_{\sigma}=0 . \\
w_{v}^{1}=\bar{\pi}_{v}^{1}-S_{v}=\tilde{\pi}_{v}^{1}+\frac{1}{2}(\Delta \pi)_{v}-S_{v}=0 .
\end{gathered}
$$

We first solve the non-cooperation profit margin $\tilde{\pi}_{\sigma}^{1}$ and obtain:

$$
\tilde{\pi}_{\sigma}^{1}=\frac{\partial \tilde{\pi}^{1}}{\partial \sigma}+\frac{\partial \tilde{\pi}^{1}}{\partial \tilde{x}_{2}} \frac{\partial \tilde{x}_{2}}{\partial \sigma}=\tilde{x}_{1}+\left(-\tilde{x}_{1}\right)\left(-\frac{1}{5}\right)=\frac{6}{5} \tilde{x}_{1}>0 .
$$


When $\sigma$ increases, firm 1's cost decreases and firm 2 has a lower advantage, implying that firm 1's profit increases under Cournot competition without subcontracting.

We now calculate a firm's share of the joint cooperation-gain margin $(1 / 2(d \Delta \pi)$ $d \sigma)){ }^{22}$ Since variables $x_{1}, x_{2}$, and $x_{s}$ respectively take the forms of $x_{1}\left(x_{s}, \sigma, v\right)$, $x_{2}\left(x_{s}, \sigma, v\right)$, and $x_{s}(\sigma, v)$, we can obtain the joint cooperation-gain margin $(d \Delta \pi d \sigma \sigma)$ as:

$$
\begin{aligned}
\frac{d(\Delta \pi)}{d \sigma} & =\left(\frac{\partial \pi}{\partial x_{1}} \frac{\partial x_{1}}{\partial x_{s}}+\frac{\partial \pi}{\partial x_{2}} \frac{\partial x_{2}}{\partial x_{s}}+\frac{\partial \pi}{\partial x_{s}}\right) \frac{\partial x_{s}}{\partial \sigma}+\left(\frac{\partial \pi^{2}}{\partial x_{1}} \frac{\partial x_{1}}{\partial \sigma}-\frac{\partial \tilde{\pi}^{2}}{\partial \tilde{x}_{1}} \frac{\partial \tilde{x}_{1}}{\partial \sigma}+\frac{\partial \pi^{1}}{\partial x_{2}} \frac{\partial x_{2}}{\partial \sigma}-\frac{\partial \tilde{\pi}^{1}}{\partial x_{2}} \frac{\partial \tilde{x}_{2}}{\partial \sigma}\right) \\
& +\left(\frac{\partial \pi^{1}}{\partial \sigma}-\frac{\partial \tilde{\pi}^{1}}{\partial \sigma}+\frac{\partial \pi^{2}}{\partial \sigma}-\frac{\partial \tilde{\pi}^{2}}{\partial \sigma}\right) \\
& =0+\left(\frac{1}{5} x_{1}-\frac{1}{5} \tilde{x}_{1}+\left(-\frac{3}{5} x_{2}\right)-\left(-\frac{3}{5} \tilde{x}_{2}\right)\right)+\left(x_{1}-\tilde{x}_{1}+0-0\right)=-\frac{12}{25} x_{s} .
\end{aligned}
$$

On the right-hand side of the first equality in equation (13), those terms in the first brackets construct the transfer effect, which describes how the cooperation profit changes through subcontracting $x_{s}$ as a resource allocation instrument when $\sigma$ changes. This effect turns out to be zero, because joint cooperation profit $(\pi)$ is maximized with respect to $x_{s}$ as shown in (6). Those terms in the second brackets and the third brackets refer to the net joint strategic effect and the net joint direct effect, respectively, following the description in footnote $18 .{ }^{23}$ As footnote 18 explains, due to $x_{1}<\tilde{x}_{1}$ and $x_{2}>\tilde{x}_{2}$, both firm 1's and firm 2's strategic effects under subcontracting are smaller than that without subcontracting, causing a negative net joint strategic effect. Similarly, the net joint direct effect turns out to be negative, because of $x_{1}<\tilde{x}_{1}{ }^{24}$

Intuitively speaking, when $\sigma$ increases, subcontracting cooperation achieves a higher profit increase than under non-cooperation, because subcontracting promotes market production to have better allocation. Therefore, the joint cooperation-gain

\footnotetext{
${ }^{22}$ We term $\pi^{i}$ and $\tilde{\pi}^{i}$ as the cooperation profit and non-cooperation profit of firm $i$, respectively. Also term $\pi$ and $\tilde{\pi}$ as the joint (cooperation) profit and joint non-cooperation profit, respectively. The terms $\Delta \pi^{i}=\pi^{i}-\tilde{\pi}$ and $\Delta \pi=\pi-\pi$ are then termed as the cooperation gain of firm $i$ and the joint cooperation gain, respectively.

${ }^{23}$ The net strategic effect in this paper is the differential joint strategic effect between cooperation and non-cooperation. Here, the joint strategic effect is also called the rent-shifting effect in international trade literature.
}

\footnotetext{
${ }^{24}$ Since firm 2 is not explicitly influenced by $\sigma$, the direct effect of $\sigma$ on firm 2's profit is zero.
} 
margin $(d \Delta \pi / d \sigma)$ becomes positive. Accordingly, when the exporting country, holding other things constant, increases its subsidy rate on the downstream good, firm 1 's competitive position is enhanced ( $\left.\pi_{\sigma}^{1}>0\right)$ and its share of joint cooperation-gain decreases $\left(1 / 2(\Delta \pi)_{\sigma}<0\right)$, due to the fact that the first effect dominates the second effect (by referring to (5), (12), and (13)). We thus obtain a positive net profit:

$$
\bar{\pi}_{\sigma}^{1}=\tilde{\pi}_{\sigma}^{1}+\frac{1}{2}(\Delta \pi)_{\sigma}=\frac{6}{5} \tilde{x}_{1}-\frac{6}{25} x_{s}=\frac{6}{5} x_{1}>0 .
$$

The net subsidy margin can be calculated as the following:

$$
\begin{aligned}
S_{\sigma} & =x_{1}+\sigma\left(\frac{\partial x_{1}}{\partial \sigma}+\frac{\partial x_{1}}{\partial x_{s}} \frac{d x_{s}}{d \sigma}\right)-v \frac{d x_{s}}{d \sigma}=x_{1}+\sigma\left[\frac{3}{5}+\left(-\frac{1}{5}\right)\left(-\frac{12}{11}\right)\right]-\left(-\frac{12}{11} v\right) \\
& =x_{1}+\frac{9}{11} \sigma+\frac{12}{11} v .
\end{aligned}
$$

While the last term $(-12 / 11 v)$ represents the tax margin, the first two terms $\left(x_{1}+9 /\right.$ $11 \sigma$ ) indicate the subsidy margin. By (14) and (15), we reduce (10) to the following form:

$$
w_{\sigma}^{1}=\bar{\pi}_{\sigma}^{1}-S_{\sigma}=\frac{6}{5} x_{1}-\left(x_{1}+\frac{9}{11} \sigma+\frac{12}{11} v\right)=\frac{1}{5} x_{1}-\left(\frac{9}{11} \sigma+\frac{12}{11} v\right)=0 .
$$

The amount $1 / 5 x_{1}$ is the residual effect of the net profit margin, while $(9 / 11 \sigma+$ $12 / 11 v)$ is the residual effect of the net subsidy margin.

Defining $x_{i} \equiv x_{i}(\sigma, v)$, we can exhibit $x_{s}=x_{s}(0,0)-(12 / 11 \sigma+25 / 11 v)$ and $x_{1}=x_{1}(0,0)+(9 / 11 \sigma+5 / 11 v)$ by equations (7) and (8). We thus obtain:

$$
w_{\sigma}^{1}=\left[\frac{1}{5} x_{1}(0,0)+\frac{9}{55} \sigma+\frac{1}{11} v\right]-\left(\frac{9}{11} \sigma+\frac{12}{11} v\right)=\frac{1}{5} x_{1}(0,0)-\left(\frac{36}{55} \sigma+v\right)=0 .
$$

The amount $(36 / 55 \sigma+v)$ is now the residual effect of the net subsidy margin while $1 / 5 x_{1}(0,0)$ remains as the residual effect of the net profit margin. Given tax rate $v$, when $x_{1}(0,0)$ increases (causing the net profit margin to increase), the subsidy rate $\sigma$ increases (to increase the net subsidy margin) so as to maximize the welfare.

To solve (11), which is the welfare margin with respect to tax $v$, we follow the previous procedure and obtain:

$$
\tilde{\pi}_{v}^{1}=\frac{\partial \tilde{\pi}^{1}}{\partial v}+\frac{\partial \tilde{\pi}^{1}}{\partial \tilde{x}_{2}} \frac{\partial \tilde{x}_{2}}{\partial v}=0
$$




$$
\begin{gathered}
(\Delta \pi)_{v}=\left(\frac{d \pi^{1}}{d x_{2}} \frac{d x_{2}}{d v}-\frac{d \tilde{\pi}^{1}}{d \tilde{x}_{2}} \frac{d \tilde{x}_{2}}{d v}+\frac{d \pi^{2}}{d x_{1}} \frac{d x_{1}}{d v}-\frac{d \tilde{\pi}^{2} \tilde{d} x_{1}}{d \tilde{x}_{1}} \frac{\left(d \pi^{1}\right.}{d v}-\frac{\partial \tilde{\pi}^{1}}{\partial v}+\frac{d \pi^{2}}{\partial v}-\frac{\partial \tilde{\pi}^{2}}{\partial v}\right) \\
=(0-0+0-0)+\left(-x_{s}-0+0-0\right)=x_{s} \\
\tilde{\pi}_{v}^{1}=\tilde{\pi}_{v}^{1}+\frac{1}{2}(\Delta \pi)_{v}=-\frac{1}{2} x_{s}<0 \\
S_{v}=\sigma \frac{\partial x_{1}}{\partial v}-\left(v \frac{\partial x_{s}}{\partial v}+x_{s}\right)=\frac{5}{11} \sigma-\left(-\frac{25}{11} v+x_{s}\right)
\end{gathered}
$$

The change of $v$ does not influence any firm's product quantity except through the channel of ensuing change of $x_{s}$, which is exactly through the transfer effect. That is, all the strategic effects (and thus the net joint strategic effect) become zero. The total transfer effect is also zero, because of the maximization problem. Moreover, tax rate $v$ does not have a direct influence on any form of a firm's profits except on firm1's before-transfer profit $\left(\pi^{1}\right)$ with a negative effect. Therefore, the non-cooperation profit margin becomes zero, while the net joint strategic effect becomes negative, causing a negative net profit margin as (19) shows.

Holding other things constant, when the exporting country increases the tax rate on the upstream good, firm 1's competitive position does not change $\left(\tilde{\pi}_{v}^{1}=0\right)$, because $\tilde{\pi}^{1}$ is free of $x_{s}$, while its share of joint cooperation-gain decreases $(1 / 2$ $\left.(\Delta \pi)_{v}<0\right)$ due to the tax burden on $x_{s}$. Combining with $(20)$, we then reduce equation (11) to the following form:

$$
w_{v}^{1}=\bar{\pi}_{v}^{1}-S_{v}=-\frac{1}{2} x_{s}-\left(\frac{5}{11} \sigma+\frac{25}{11} v-x_{s}\right)=-\sigma+\left[-\frac{75}{22} v+\frac{1}{2} x_{s}(0,0)\right]=0 .
$$

Due to zero strategic effects, the net profit margin $\left(-1 / 2 x_{s}\right)$ is totally canceled out by the term $-x_{s}$ in the net subsidy margin. Therefore, the right-hand side of the third equality in (21) indicates the residual effect of net subsidy margin, in which $-\sigma$ represents the subsidy margin while $-75 / 22 v+1 / 2 x_{s}(0,0)$ is the tax margin. Under welfare maximization for a given $\sigma$, it is profitable to set a higher tax $v$ when $x_{s}(0,0)$ increases (which then increases the tax margin).

Through (16) and (21), we can see that when both $\sigma$ and $v$ are negative (i.e., taxing the downstream export and subsidizing the upstream export), the residual effect of the net subsidy margin becomes negative. Thus, both $w_{\sigma}^{1}>0$ and $w_{v}^{1}>0$, implying that it is always more profitable for the exporting country when both trade policies $\sigma$ and $v$ increase. We hence build the first Proposition: 
Proposition 1. It is never an optimal trade policy for the exporting country to tax the downstream export and to subsidize the upstream export at the same time.

Solving simultaneously equations (16) and (21), we obtain the optimal subsidy and tax level as the following: ${ }^{25}$

$$
\begin{aligned}
\sigma^{*} & =\frac{11}{298}\left[15 x_{1}(0,0)-11 x_{s}(0,0)\right] \\
v^{*} & =\frac{11}{745}\left[18 x_{s}(0,0)-11 x_{1}(0,0)\right]
\end{aligned}
$$

Directly through (22) and (23) or by the graphs in the Appendix, we can obtain the possible optimal trade policies for the exporting country, as in Proposition 2.

Proposition 2. When the subcontracted quantity is sufficiently large such that $x_{s}(0,0)>15 / 11 x_{1}(0,0)$ it is optimal for the exporting country to tax both exports. When the subcontracted quantity is sufficiently small such that $x_{s}(0,0)<11 / 18 x_{1}(0,0)$ it is optimal for the exporting country to subsidize both exports. It is otherwise optimal for the exporting country to subsidize the downstream export, but to also tax the upstream export.

Proof. Direct implication of (22) and (23).

Given subsidy rate $\sigma$, a larger $x_{s}$ implies a larger cooperation gain, which gives the government an incentive to set a higher tax on the upstream export. On the other hand, a larger $x_{1}$ implies a smaller cooperation gain, which gives the government an incentive to set a higher subsidy on the downstream export so as to switch more resources away from producing the subcontracted product. Therefore, when $x_{\mathrm{s}}(0,0)$ is sufficiently large and $x_{1}(0,0)$ is sufficiently small, a higher tax on the upstream export and a lower-down-to-negative subsidy on the downstream export may turn out to be an equilibrium. In some sense, the subcontracting cooperation lowers the average cost of the final good, improves the terms of trade (TOT), and gives the exporting country an incentive to tax both exports in order to transfer to itself part of the importing country's consumer surplus.

When $x_{\mathrm{s}}(0,0)$ is sufficiently small and $x_{1}(0,0)$ is sufficiently large, a lower-down-

\footnotetext{
${ }^{25}$ The second-order sufficient conditions are satisfied: $d^{2} w^{1} / d \sigma^{2}=-36 / 55<0$ and $d^{2} w^{1} / d v^{2}=-75 / 22<0$.
} 
to-negative tax on the upstream export and a higher subsidy on the downstream export may in contrast turn out to be an equilibrium. In this case, subsidizing both exports helps the exporting firm capture a lager share of the imperfectly competitive rent. Accordingly, a moderately large $x_{\mathrm{s}}(0,0)$ and $x_{1}(0,0)$ lead to an equilibrium with a moderate tax on the upstream export and a moderate subsidy on the downstream export. The equilibria of Proposition 2 can be shown as in the Appendix.

Proposition 2 shows a different conclusion from what has been shown in the literature. Spencer and Jones (1991) show that only the parallel trade policy could be optimal for the exporting country: taxing the exports of both products if the difference in profit margins from the exports of the intermediate good and the final good is positive, while subsidizing the exports of both products if the difference in profit margins is negative. LCS (2003) instead shows that the exporting country imposes a different trade policy on each export when some conditions are met. Moreover, a parallel trade policy involving a subsidy on both exports is never achievable.

By comparative statics, we can also derive that $d \sigma^{*} / d t<0$ and $d v^{*} / d t>0$ from (22) and (23), because $x_{s}(0,0)$ increases while $x_{1}(0,0)$ decreases when exogenous variable $t$ increases. That is, a higher importing tariff of the importing country on the exporting firm's downstream export increases the exporting firm's sales cost, which then increases the relative profitability of the subcontracted export. This then leads the exporting country to impose a higher tax on the subcontracted export and a lower subsidy on the downstream export in order to maximize welfare.

We define now a "more aggressive trade policy" as when the exporting country imposes a higher subsidy and/or a lower tax on exports, or when the importing country employs a higher tariff on imports. We thus build the following Corollary:

Corollary 1. When the importing country uses a more aggressive trade policy, the exporting country chooses a less aggressive trade policy in response.

\section{A Pure Subcontractor}

When it is not profitable for the exporting firm to export the downstream product $x_{1}$ due to an expensive downstream marketing cost $m_{1}$, the first-order condition in (3) is always less than zero. In this case, the downstream market then becomes a 
monopoly of firm 2, and firm 1 becomes a pure subcontractor. ${ }^{26}$

By backward induction, we obtain the equilibrium output for firm 2 in stage 2:

$$
x_{2}=\tilde{x}_{2}+\frac{1}{3} x_{s}, \text { where } \tilde{x}_{2}=\frac{1}{3}\left(a-m_{2}-\beta\right) .
$$

This shows that $x_{2}$ increases when $x_{s}$ increases, because subcontracting can effectively reduce firm 2's production cost. In stage 1, anticipating $x_{1}$ and $x_{2}$, the two firms negotiate over the transfer payment for subcontracting. Under a Nash bargaining solution, the firms choose subcontracted output $x_{s}$ to maximize the joint profit $\pi$, which is equal to $\pi^{1}+\pi^{2}$ where:

$$
\pi^{1}=-c_{1} x_{s}-v x_{s}, \quad \text { and } \pi^{2}=\left(a-x_{2}-m_{2}\right) x_{2}-\beta\left(x_{2}-x_{s}\right)-\frac{1}{2}\left(x_{2}-x_{s}\right)^{2} .
$$

Following the previous section, we thus obtain the optimal subcontracted quantity and the derived equilibrium output of firm 2 as follows:

$$
x_{s}=\frac{1}{2}\left(a-m_{2}-3 c_{1}-3 v\right)+\beta, \quad \text { and } x_{2}=\frac{1}{2}\left(a-m_{2}-c_{1}-v\right) .
$$

This shows that if firm 1's relative marginal cost increases due to the increase of $c_{1}$ and/or $v$, then there is less cost savings for firm 2 under subcontracting cooperation. The result is a smaller $x_{s}$ and then a smaller $x_{2}$.

In the prior stage, on the expectation of $x_{1}, x_{2}, x_{s}$, and $T$, the exporting country chooses a tax rate $(v)$ on its only export (i.e., the subcontracted good) so as to maximize its social welfare $w^{1}=\bar{\pi}^{-1}-S$, where $S=-v x_{s}$. The first-order condition turns out to be:

$$
w_{c}^{1}=\bar{\pi}_{v}^{1}-S_{v}=\frac{1}{2} x_{s}-\frac{3}{2} v=0,
$$

where we have:

$$
\begin{gathered}
\bar{\pi}_{v}^{1}=\frac{1}{2}(\Delta \pi)_{v}=\frac{1}{2}\left(\frac{\partial \pi^{1}}{\partial v}+\frac{\partial \pi^{2}}{\partial v}-\frac{\partial \tilde{\pi}^{2}}{\partial v}\right)=\frac{1}{2}\left(-x_{s}+0-0\right)=-\frac{1}{2} x_{s}<0 \\
S_{v}=-x_{s}-v \frac{d x_{s}}{d v}=-x_{s}+\frac{3}{2} v .
\end{gathered}
$$

Since there is no competition in the downstream market (because firm 1 does

\footnotetext{
${ }^{26}$ For example, in Taiwan's high-tech industry, most firms export only subcontracted products.
} 
not manufacture product $x_{1}$ ), all the strategic effects disappear and the noncooperation profit margin becomes zero. This results in a negative net profit margin of firm 1 as from (28), because an increase in tax $v$ causes a decrease in the joint cooperation-gain. As usual, when the tax $v$ is too high, the government's net tax margin decreases (i.e., net subsidy margin increases) if tax $v$ increases, as in (29). Since the loss part $\left(-x_{s}\right)$ of the government's net subsidy margin outweighs firm 1's net profit margin $\left(-1 / 2 x_{s}\right)$, the tax $v$ must be positive and high enough to achieve the maximum social welfare. This implies that subsidizing the subcontracted good is never optimal, and that the greater $x_{s}$ is, the higher the tax $v$ will be for achieving equilibrium. Defining $x_{\mathrm{s}}$ in (26) as $x_{\mathrm{s}}(v)$, we see that $x_{s} \equiv x_{s}(v)=x_{s}(0)-3 / 2 v, \quad$ where $x_{s}(0)=1 / 2\left(a-m_{2}-3 c_{1}\right)+\beta$. We can now obtain the exporting country's optimal tax rate as (30) and subsequently build Proposition 3 :

$$
v=\frac{2}{9} x_{s}(0)
$$

Proposition 3. When the subcontracted good is the single exporting product, the only optimal trade policy for the exporting country is to tax the single export. When the quantity of the export $x_{s}(0)$ increases, the optimal tax increases.

Due to the fact that firm 1 is the single subcontractor and that firm 2 is required to share its monopoly profit with firm 1 under Nash bargaining and ex ante subcontracting, the tax burden on firm 1's subcontracted export is partly transferred to firm 2, increasing firm 2's cost and the market price. In some sense, part of the importing country's consumer surplus is thus transferred to the exporting country's welfare through a tax. However, in LCS (2003), in which an ex post subcontract is used, the market output (and therefore price) is determined before subcontracting negotiation, indicating that the importing country's consumer surplus is fixed and no any consumer surplus transfer from the importing country to the exporting country through any exporting trade policy. Subsequently, LCS finds that when the subcontracted good is the single export, a tax or a subsidy could be an optimal trade policy for the exporting country, depending on the magnitude of its subcontracting profit gain. Our findings also differ from Spencer and Brander (1983), who show that, when the intermediate good is the single export, a definitely optimal policy for the exporting country is to subsidize the single export in order to help the domestic firm capture a larger share of the imperfectly competitive rent. 


\section{Concluding Remarks}

Taking into account the issue of ex ante international subcontracting, this paper examines the optimal trade policies of an exporting country when the exporting firm exports the downstream product as well as the subcontracted product. The exporting firm and the importing firm (in the importing country) ex ante negotiate over a subcontract in which part of the production of the importing firm's output is consigned to the exporting firm, and then they both Cournot-compete for sales of the downstream product in the importing country. We show that the optimal trade policy for the exporting country can be either a different trade policy or a parallel trade policy on each export. However, a different trade policy involving taxing the downstream export and subsidizing the upstream export is not ever an optimal policy.

Secondly, if we define a "more aggressive trade policy" as when the exporting country imposes a higher subsidy and/or a lower tax on exports, or when the importing country employs a higher tariff on imports, then we find that the exporting country imposes a less aggressive trade policy in response, given that the importing country imposes a more aggressive trade policy.

Thirdly, when the subcontracted product is the single export due to the exporting firm having very high marketing costs, taxing the single exporting product is the only optimal trade policy for the exporting country. Moreover, when the quantity of the subcontracted good increases, the exporting country increases its tax rate.

This paper can be extended to a take-or-leave-it model in the subcontracting stage. The importing firm can unilaterally determine the quantity of its output to subcontract out and also its transfer price, and then the subcontractor (the exporting firm) decides whether or not to take the contract. It implies the importing firm has all the bargaining power. On the other hand, constructing the downstream market as a Stackelberg model or a price competition model can be another extension.

Received 5 December 2006, Accepted 10 April 2007

\section{Appendix}

Demonstrating the equivalence between Nash bargaining solution and the joint profit maximization:

Let $\eta$ and $\gamma$ denote the bargaining power of firm 1 and firm 2, respectively. If 
both firms reach a subcontracting agreement, then each receives $\bar{\pi}$, while each firm gets $\pi^{i}$ if no agreement is achieved. By defining $y \equiv\left(\bar{\pi}^{1}-\tilde{\pi}^{1}\right)=\left(\pi^{1}+T-\tilde{\pi}^{1}\right)$ and $z \equiv\left(\bar{\pi}^{2}-\tilde{\pi}^{2}\right)=\left(\pi^{2}-T-\tilde{\pi}^{2}\right)$, the Nash bargaining over both $x_{s}$ and $T$ solves the following objective function:

$$
N=y^{\eta} z^{\gamma}
$$

Taking derivative with respect to $x_{s}$ and $T$, we get:

$$
\begin{gathered}
\frac{d N}{d x_{s}}=y^{\eta-1} z^{\gamma-1}\left[\eta z\left(\frac{d \pi^{1}}{d x_{s}}+\frac{d T}{d x_{s}}\right)+\gamma y\left(\frac{d \pi^{2}}{d x_{s}}+\frac{d T}{d x_{s}}\right)\right]=0 . \\
\frac{d N}{d T}=y^{\eta-1} z^{\gamma-1}[\eta z-\gamma y]=0 .
\end{gathered}
$$

By (A2), we obtain $\eta z-\gamma y=0$, which implies

$$
T=\frac{\eta}{\eta+\gamma}\left(\tilde{\pi}^{2}-\tilde{\pi}^{2}\right)-\frac{\gamma}{\eta+\gamma}\left(\pi^{1}-\tilde{\pi}^{1}\right)
$$

Substituting $\eta z=\gamma y$ and $\frac{d T}{d x_{s}}=\frac{1}{\eta+\gamma}\left(\eta \frac{d \pi^{2}}{d x_{s}}-\gamma \frac{d \pi^{1}}{d x_{s}}\right)$ for (A1), we obtain

$$
\begin{aligned}
\frac{d N}{d x_{s}} & =y^{\eta-1} z^{\gamma-1}\left[\eta z \frac{\eta}{\eta+\gamma}\left(\frac{d \pi^{1}}{d x_{s}}+\frac{d \pi^{2}}{d x_{s}}\right)+\gamma y \frac{\gamma}{\eta+\gamma}\left(\frac{d \pi^{1}}{d x_{s}}+\frac{d \pi^{2}}{d x_{s}}\right)\right] \\
& =y^{\eta-1} z^{\gamma-1} \eta z \frac{d \pi}{d x_{s}}=0 .
\end{aligned}
$$

It requires that

$$
\frac{d \pi}{d x_{s}}=0
$$

Therefore, Nash bargaining over both the subcontracted quantity and the transfer payment is equivalent to that choosing the subcontracted quantity by maximizing the joint profit and splitting the maximum joint profit through the Nash bargaining over the transfer payment.

After subcontracting, each firm's net profits are as follows:

$$
\bar{\pi}^{1}=\pi^{1}+T=\frac{1}{2} \Delta \pi+\tilde{\pi}^{1}, \text { and } \bar{\pi}^{2}=\pi^{2}-T=\frac{1}{2} \Delta \pi+\tilde{\pi}^{2}
$$

The basic mechanism in Nash bargaining is to share out one firm's profit gain to 
the other firm according to the corresponding bargaining power. Firm 1 pays out $1 / 2\left(\pi^{1}-\tilde{\pi}^{1}\right)$ to firm 2 , while firm 2 needs to share out $1 / 2\left(\pi^{2}-\tilde{\pi}^{2}\right)$ to firm 1 . Thus, the transfer payment (from firm 2 to firm 1) equals $1 / 2\left(\pi^{2}-\tilde{\pi}^{2}\right)-1 / 2\left(\pi^{1}-\tilde{\pi}^{1}\right)$. It can also be represented by firm 1's share of joint cooperation gain $(1 / 2 \Delta \pi)$ minus its profit increase due to cooperation $\left(\pi^{1}-\tilde{\pi}^{1}\right)$. On the other hand, each firm's net profit equals its share of joint cooperation gain $(1 / 2 \Delta \pi)$ plus its non-cooperation profit (i.e., disagreement profit, $\tilde{\pi}^{i}$ ).

Deriving the first-order condition with respect to $\sigma$ of country l's welfare function:

$$
\begin{aligned}
& \frac{d(\Delta \pi)}{d \sigma}= {\left[\frac{\partial \pi}{\partial x_{1}}\left(\frac{\partial x_{1}}{\partial \sigma}+\frac{\partial x_{1}}{\partial x_{s}} \frac{\partial x_{s}}{\partial \sigma}\right)+\frac{\partial \pi}{\partial x_{2}}\left(\frac{\partial x_{2}}{\partial \sigma}+\frac{\partial x_{2}}{\partial x_{s}} \frac{\partial x_{s}}{\partial \sigma}\right)+\frac{\partial \pi}{\partial x_{s}} \frac{\partial x_{s}}{\partial \sigma}+\frac{\partial \pi}{\partial \sigma}\right] } \\
&- {\left[\frac{\partial \tilde{\pi}}{\partial \tilde{x}_{1}} \frac{\partial \tilde{x}_{1}}{\partial \sigma}+\frac{\partial \tilde{\pi}}{\partial \tilde{x}_{2}} \frac{\partial \tilde{x}_{2}}{\partial \sigma}+\frac{\partial \tilde{\pi}}{\partial \sigma}\right] } \\
&=(\left.\frac{\partial \pi}{\partial x_{1}} \frac{\partial x_{1}}{\partial x_{s}}+\frac{\partial \pi}{\partial x_{2}} \frac{\partial x_{2}}{\partial x_{s}}+\frac{\partial \pi}{\partial x_{s}}\right) \frac{\partial x_{s}}{\partial \sigma}+\frac{\partial \pi}{\partial x_{1}} \frac{\partial x_{1}}{\partial \sigma}+\frac{\partial \pi}{\partial x_{2}} \frac{\partial x_{2}}{\partial \sigma}+\frac{\partial \pi}{\partial \sigma}-\left[\frac{\partial \tilde{\pi}}{\partial \tilde{x}_{1}} \frac{\partial \tilde{x}_{1}}{\partial \sigma}+\frac{\partial \tilde{\pi}}{\partial \tilde{x}_{2}} \frac{\partial \tilde{x}_{2}}{\partial \sigma}+\frac{\partial \tilde{\pi}}{\partial \sigma}\right] \\
&=(\left.\frac{\partial \pi}{\partial x_{1}} \frac{\partial x_{1}}{\partial x_{s}}+\frac{\partial \pi}{\partial x_{2}} \frac{\partial x_{2}}{\partial x_{s}}+\frac{\partial \pi}{\partial x_{s}}\right) \frac{\partial x_{s}}{\partial \sigma}+\left(\frac{\partial \pi^{2}}{\partial x_{1}} \frac{\partial x_{1}}{\partial \sigma}+\frac{\partial \pi^{1}}{\partial x_{2}} \frac{\partial x_{2}}{\partial \sigma}+\frac{\partial \pi}{\partial \sigma}\right)-\left(\frac{\partial \tilde{\pi}^{2}}{\partial \tilde{x}_{1}} \frac{\partial \tilde{x}_{1}}{\partial \sigma}+\frac{\partial \tilde{\pi}^{1}}{\partial x_{2}} \frac{\partial \tilde{x}_{2}}{\partial \sigma}+\frac{\partial \tilde{\pi}}{\partial \sigma}\right) \\
&=\left(\frac{\partial \pi}{\partial x_{1}} \frac{\partial x_{1}}{\partial x_{s}}+\frac{\partial \pi}{\partial x_{2}} \frac{\partial x_{2}}{\partial x_{s}}+\frac{\partial \pi}{\partial x_{s}} \frac{\partial x_{s}}{\partial \sigma}+\left(\frac{\partial \pi^{2}}{\partial x_{1}} \frac{\partial x_{1}}{\partial \sigma}-\frac{\partial \tilde{\pi}^{2}}{\partial \tilde{x}_{1}} \frac{\partial \tilde{x}_{1}}{\partial \sigma}+\frac{\partial \pi^{1}}{\partial x_{2}} \frac{\partial x_{2}}{\partial \sigma}-\frac{\partial \tilde{\pi}^{1}}{\partial x_{2}} \frac{\partial \tilde{x}_{2}}{\partial \sigma}\right)\right. \\
&+\left(\frac{\partial \pi^{1}}{\partial \sigma}-\frac{\partial \tilde{\pi}^{1}}{\partial \sigma}+\frac{\partial \pi^{2}}{\partial \sigma}-\frac{\partial \tilde{\pi}^{2}}{\partial \sigma}\right)
\end{aligned}
$$

Demonstrating the three possible equilibria in Proposition 2:

By equations (17) and (22), we can draw the best-response curves $v(\sigma)$ and $\sigma(v)$ as the diagrams below, which have slopes $-36 / 55$ and $-11 / 150$, respectively. Therefore, if $1 / 5 x_{1}(0,0)>11 / 75 x_{s}(0,0)$ and $1 / 36 x_{1}(0,0)<1 / 2 x_{s}(0,0)$, then the equilibrium trade policy has both positive $\sigma$ and $v$, as shown in Case 1 . When $1 / 5 x_{1}(0,0)<11 / 75 x_{s}(0,0)$ and $1 / 36 x_{1}(0,0)<1 / 2 x_{s}(0,0)$, then as Case 2 shows, the equilibrium trade policy is when $\sigma<0$ and $v>0$. Finally, Case 3 demonstrates the situation when $1 / 5 x_{1}(0,0)>$ $11 / 75 x_{s}(0,0)$ and $1 / 36 x_{1}(0,0)>1 / 2 x_{s}(0,0)$, in which $\sigma>0$ and $v<0$ represent an equilibrium trade policy for the exporting country. 
Case 1: $11 / 18 x_{1}(0,0)<x_{s}(0,0)<15 / 11 x_{1}(0,0)$

Case 2: $x_{s}(0,0)>15 / 11 x_{1}(0,0)$
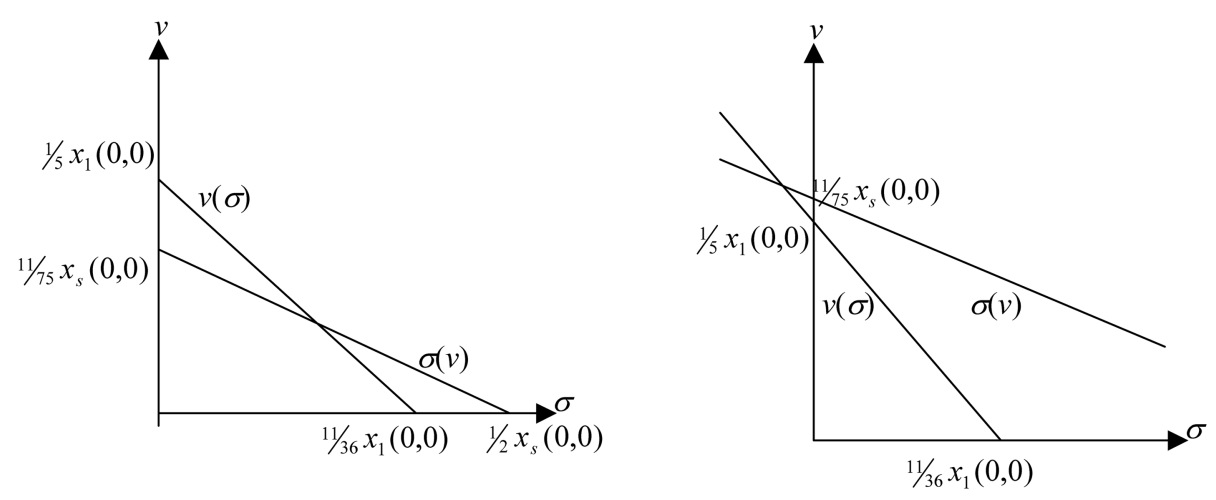

Case 3: $x_{s}(0,0)<11 / 18 x_{1}(0,0)$

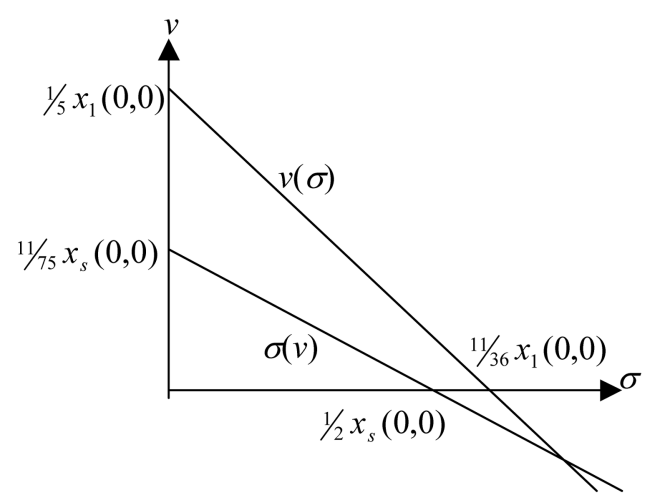

\section{References}

Brander, J.A., and B.J. Spencer, 1981, "Tariffs and the Extraction of Foreign Monopoly Rents Under Potential Entry," Canadian Journal of Economics 14, 371-389.

Brander, J.A., and B.J. Spencer, 1984a, "Trade Welfare: Tariffs and Cartels," Journal of International Economics 16, 227-242.

Brander, J.A., and B.J. Spencer, 1984b, "Tariff Protection and Imperfect Competition," in Henry Kierzkowski, ed., Monopolistic Competition and International Trade (Oxford University Press, Oxford).

Brander, J.A., and B.J. Spencer, 1985, "Export Subsidies and International Market Share Rivalry," Journal of International Economics 18, 83-100.

Bulow, J.I., J.D. Geanakoplos, and P.D. Klemperer, 1985, "Multimarket Oligopoly: Strategic Substitutes and Complements," Journal of Political Economy 93, 488-511. Collie, D.R., 1997, "Bilateralism Is Good: Trade Blocs and Strategic Export Subsidies," 
Oxford Economic Papers 49, 504-520.

Chen, Y., J. Ishikawa, and Z. Yu, 2004, "Trade Liberalization and Strategic Outsourcing," Journal of International Economics 63:419-436.

The Economist, 1995, “The outing of Outsourcing," November 25: 57-58.

Grossman, G. and E. Helpman, 1999, "Incomplete Contract and Industrial Organization," National Bureau of Economic Research Working paper No. 7303.

Hummels, D., J. Ishii, and K-M. Yi, 2001, “The Nature and Growth of Vertical Specialization in World Trade," Journal of International Economics 54: 75-96.

Holm, P., 1997, "Vertical Integrated Oligopoly and International Trade Policy," Canadian Journal of Economics 30, 194-207.

Ikeda, M., 1989, “A Comparative Study of International Subcontracting System.” In K. Shibagaki, M. Trevor, and T. Abo, eds., Japanese and European Management: Their International Adaptability. Tokyo: University of Tokyo Press.

Fubon Investment Service, 2002, 2001 Industrial Reports. Taipei: Fubon Financial.

Kamien, M.I., L. Li, and D. Samet, 1989, "Bertrand Competition with Subcontracting," RAND Journal of Economics 20:4, 553-567.

Liang, W-J., H-C. Chen, and M-S. Shi, 2003, "Subcontracting and International Trade Policy," Journal of Economic Integration 18(2): 372-390.

Market Intelligence Center (MIC), 2002, Information Technology Industry (III). Taipei: Institute for Information Industry.

Pack, H. and K. Saggi, 2001, "Vertical Technology Transfer via International Outsourcing," Journal of Development Economics 65: 389-415.

Shy, O. and Stenbacka, R., 2003, "Strategic Outsourcing," Journal of Economic Behavior \& Organization 50: 203-224.

Spencer, B.J., and J.A. Brander, 1983, "International R\&D Rivalry and Industrial Strategy," Review of Economics Studies 50:4, 707-722.

Spencer, B.J., and R.W. Jones, 1991, "Vertical Foreclosure and International Trade Policy," Review of Economics Studies 58:1, 153-170.

Spencer, B.J., and R.W. Jones, 1992, "Trade and Protection in Vertically Related Markets," Journal of International Economics 32, 31-55.

Spiegel, Y., 1993, “Horizontal Subcontracting," RAND Journal of Economics 24:4, 570590. 